\title{
Diagnóstico e análise da degradação ambiental: estudo de caso do açude Bodocongó
}

\author{
Diagnosis and analysis of environmental degradation: a case study of the Bodocongó reservoir \\ Diagnóstico y análisis de la degradación ambiental: un estudio de caso del embalse de Bodocongó
}

Recebido: 25/09/2021 | Revisado: 01/10/2021 | Aceito: 03/10/2021 | Publicado: 05/10/2021

\author{
Mauricio Donizeti Pereira Filho \\ ORCID: https://orcid.org/0000-0002-5053-8920 \\ Universidade Federal de Campina Grande, Brasil \\ E-mail: mpereirafilho1@ gmail.com \\ Maria Sallydelândia Sobral de Farias \\ ORCID: https://orcid.org/0000-0002-3255-2024 \\ Universidade Federal de Campina Grande, Brasil \\ E-mail: sallyfarias@hotmail.com \\ Josilene Pereira Lima \\ ORCID: https://orcid.org/0000-0002-4624-5009 \\ Universidade Federal de Pernambuco, Brasil \\ E-mail: josilenelima2003@yahoo.com.br \\ Deyzi Santos Gouveia \\ ORCID: https://orcid.org/0000-0003-3775-2727 \\ Universidade Federal de Campina Grande, Brasil \\ E-mail: deyzigouveia2021@gmail.com \\ Júlia Soares Pereira \\ ORCID: https://orcid.org/0000-0002-6495-1169 \\ Universidade Federal de Campina Grande, Brasil \\ E-mail: julia_eng@hotmail.com
}

\begin{abstract}
Resumo
A degradação ambiental de bacias hidrográficas urbanas tem trazido grandes prejuízos à sua rede de drenagem e consequentemente a toda sociedade do entorno. A gestão ineficaz, associado à falta de políticas públicas, no que se refere a fiscalização, ao saneamento básico, acaba promovendo o descarte inadequado de esgoto e de lixo nos corpos hídricos presentes nas áreas urbanas. As ações antrópicas acometidas no perímetro do açude de Bodocongó, ocasionam impactos negativos tais como a contaminação da água, do solo e a processos erosivos. $\mathrm{O}$ aumento populacional em volta do açude, criação de Parque público, condomínios habitacionais e a falta de fiscalização, trouxeram grandes impactos na bacia do corpo d'água. O constante aporte de efluentes domésticos e industriais, deixaram o manancial Hipereutrofizado, com elevados índices de coliformes totais. Se faz necessário ações educativas e políticas públicas voltadas para a recuperação do manancial de importância histórica para a Cidade de Campina Grande - Paraíba.
\end{abstract}

Palavras-chave: Reservatório urbano; Ecossistema aquático; Sustentabilidade.

\begin{abstract}
The environmental degradation of urban watersheds has brought great damage to its drainage network and, consequently, to the entire society around it. Ineffective management, associated with the lack of public policies, with regard to inspection and basic sanitation, ends up promoting the inadequate disposal of sewage and garbage in water bodies present in urban areas. Anthropogenic actions on the perimeter of the Bodocongó reservoir cause negative impacts such as water and soil contamination and erosion processes. The population increase around the dam, the creation of a public park, housing condominiums and the lack of inspection, brought great impacts on the water body basin. The constant input of domestic and industrial effluents left the source hypereutrophic, with high levels of total coliforms. Educational actions and public policies aimed at recovering the historically important source for the city of Campina Grande are necessary.
\end{abstract}

Keywords: Urban reservoir; Aquatic ecosystem; Sustainability.

\section{Resumen}

La degradación ambiental de las cuencas hidrográficas urbanas ha traído un gran daño a su red de drenaje y, en consecuencia, a toda la sociedad que la rodea. La gestión ineficaz, asociada a la falta de políticas públicas, en materia de fiscalización y saneamiento básico, acaba promoviendo la inadecuada disposición de aguas servidas y basura en los cuerpos de agua presentes en las zonas urbanas. Las acciones antrópicas en el perímetro del embalse de Bodocongó provocan impactos negativos como la contaminación del agua y el suelo y procesos de erosión. El aumento de población en torno a la presa, la creación de un parque público, condominios habitacionales y la falta de inspección, 
trajeron grandes impactos en la cuenca del cuerpo de agua. El aporte constante de efluentes domésticos e industriales dejó la fuente hipereutrófica, con altos niveles de coliformes totales. Son necesarias acciones educativas y políticas públicas encaminadas a recuperar la fuente históricamente importante para la ciudad de Campina Grande.

Palabras clave: Embalse urbano; Ecosistema acuático; Sustentabilidad.

\section{Introdução}

A degradação ambiental de bacias hidrográficas urbanas tem trazido grandes prejuízos à sua rede de drenagem e consequentemente a toda sociedade do entorno. O crescimento das grandes cidades e a busca por ocupação de áreas de forma irregulares pressionam os impactos negativos destes ambientes.

A falta de gestão, associado à falta de políticas públicas no que se refere a fiscalização, ao saneamento básico, acaba promovendo o descarte inadequado de esgoto e de lixo nos corpos hídricos presentes nas áreas urbanas, ocasionando alterações negativas do ecossistema aquático, alterando a vida e o crescimento dos organismos, refletindo na qualidade da água e a deixando imprópria ao consumo humano e outras atividades.

No que diz respeito a problemática ambiental, as áreas urbanas no Brasil apresentam vários problemas que são negligenciados pela gestão pública, destacam-se aqueles vinculados a precarização do saneamento básico. Na maioria dos municípios brasileiros e no caso específico da cidade de Campina Grande - PB, a coleta e deposição final do lixo, assim como o tratamento e destinação dos esgotos ocorrem de forma inadequada, provocando, entre outros, a poluição de toda bacia hidrográfica e seus recursos naturais. Conforme Rebouças (2004), no Brasil, "cerca de 64\% das empresas de abastecimento d'água das cidades mais importantes e regiões metropolitanas não coletam, sequer, os esgotos domésticos que produzem.” Essa realidade compromete a qualidade dos recursos hídricos.

O açude Bodocongó é um exemplo de manancial localizado em área urbana, onde evidencia-se o descaso do poder público. Segundo Morais Neto et al. (2016), um ambiente que nos primórdios serviu até de lazer, recreação e cultura, para diferentes classes sociais da cidade, ao longo do tempo foi se encontrando praticamente assoreado face ao processo de degradação ambiental de toda sua bacia hidrográfica. Refletindo em um processo de vulnerabilidade para população local, estando exposta a possíveis riscos, com graves problemas urbanos, ambientais e de saúde. É necessário, uma eficiente gestão ambiental, visto a importância do açude para a cidade e seu grande potencial paisagístico.

Para um planejamento estratégico a ser aplicado na gestão dos recursos hídricos, o conhecimento da qualidade da água é importante para um diagnóstico do ecossistema aquático, possíveis danos a população, níveis de contaminação e definições dos diversos usos a que pode ser destinado o recurso. Atualmente, apenas uma margem do açude Bodocongó foi realizado uma reabilitação para lazer, no entanto, o assoreamento e o depósitos de resíduos estão presentes na área, necessitando de pesquisas que venham a gerar informações sobre a condição atual do manancial.

\section{Metodologia}

O Açude de Bodocongó está localizado na Cidade de Campina Grande - PB, com coordenadas 07 $13^{\prime} 50^{\prime \prime} \mathrm{Sul}, 35^{\circ}$ 52' 52" Oeste, no planalto da Borborema. O trecho do estudo compreende um afluente que leva o nome do açude, distante aproximadamente $11 \mathrm{~km}$ de suas nascentes mais longa, pertencente a sub Bacia do Riacho Bodocongó e se estende do sul do Município de Montadas até o bairro da Catingueira em Campina Grande, desenvolvendo uma extensão de 25 Km no sentido Norte-Sul.

A metodologia empregada baseia-se nas observações e anotações in loco, para exploração da área e registro dos principais pontos de degradação. Também em fundamentação teórica adquirida durante os anos de graduação, ainda em andamento. 
Para a coleta e transporte das amostras de água utilizou-se como referência o Guia Nacional de Coleta e Preservação de Amostras (Brandão et al, 2011). Na avaliação de qualidade de água do manancial foram realizadas duas coletas, a primeira para análise físico-química, acondicionada em garrafa pet de 2 litros, e a segunda para análise microbiológica, acondicionada em frasco estéril com tiossulfato de sódio. Em seguida, as amostras foram encaminhadas, em condições de transporte adequado, para análise no LABDES - Laboratório de Referência em Dessalinização, na Universidade Federal de Campina Grande.

Foram tomados como base os seguintes arcabouços jurídicos nacionais:

Portaria $\mathrm{N}^{\circ}$ 2.914, de 12 de dezembro de 2011 que dispõe sobre os procedimentos de controle e de vigilância da qualidade da água para consumo humano e seu padrão de potabilidade; Portaria de consolidação GM/MS N. 888 de 4 de maio de 2021, que altera a Portaria de consolidação n. 5 Anexo XX de setembro de 2017.

Resolução do CONAMA N 357 de 17 de março de 2005 que dispõe sobre a classificação dos corpos de água e diretrizes ambientais para o seu enquadramento, bem como estabelece as condições e padrões de lançamento de efluentes, e dá outras providências;

Resolução do CONAMA n 274, de 29 de novembro de 2000 que define os critérios de balneabilidade em águas brasileiras.

Para o cálculo do Índice do Estado Trófico (IET) em reservatório, a partir dos valores de fósforo total, foi utilizado a Equação 01 de Lamparelli (2004):

$$
\text { IET = 10. }(6-(1,77-0,42 .(\ln . P T) / \ln 2)) \quad \text { Equação } 01
$$

Onde: PT = Fósforo total em mg/L.

Para avaliação da urbanização no entorno do Açude de Bodocongó, foi considerado o intervalo de tempo de 14 anos, utilizando imagens do sensor TM - Landsat 5 (29/08/2007) e do sensor OLI - Landsat 8 (28/03/2021). Estas foram adquiridas por meio do Serviço Geológico dos Estados Unidos (USGS). As imagens foram reprojetadas para o sistema de coordenadas UTM (SIRGAS 2000, Zona 24S).

Utilizou-se também, o Índice de Área Construída por Diferença Normalizada (Normalised Difference Built-up Index NDBI), que permite realizar a estimativa de áreas com superfícies edificadas ou em construção em comparação com as áreas naturalizadas usuais com vegetação ou nua.

O NDBI (Equação 02) é a razão das diferenças de refletividade para a banda do infravermelho médio) e a banda do infravermelho.

NDBI $=(($ SWIR-NIR $)) /(($ SWIR+NIR $)) \quad$ Equação 02

Onde: SWIR corresponde a banda do infravermelho médio e NIR a banda do infravermelho próximo.

O software utilizado para realizar o processamento foi o QGis (versão - 3.10.8 A Coruña) por ser gratuito, e possuir uma interface gráfica simples e intuitiva. Os índices foram gerados utilizando a calculadora raster. 


\section{Resultados e Discussão}

Em visitas a campo, foram identificadas várias fontes de contaminação no canal de Bodocongó, lançamentos de resíduos sólidos e líquidos de diversas origens.

As águas provenientes das atividades industriais são somadas aos esgotos das residências localizadas nos Bairros vizinhos, Monte Santo e Araxá, também despejados diretamente e sem nenhum tratamento prévio no Riacho de Bodocongó.

Segundo estudos do Instituto Brasileiro de Geografia e Estatística (IBGE, 2010), o município de Campina Grande possui um sistema de esgotamento sanitário municipal que abrange 84,1\%, embora na prática boa parte da cidade sofre com a falta de planejamento e execução nas ligações de esgotos domésticos, ocorrendo com frequência a realização de lançamentos clandestinos na rede de drenagem pluvial, o que impacta diretamente os corpos d'água.

Essa prática, vai em desacordo com a legislação ambiental em vigor no país, sendo uma das fontes mais perigosas de contaminação das águas. A poluição industrial é capaz de exterminar a vida aquática, e causar sérios danos à cadeia alimentar, sobretudo ao homem, que sobrevive dessas águas e retira dela, através da pesca um meio para suprir suas necessidades alimentares.

O lançamento de efluentes, somado à outras práticas ilegais, de forma contínua e ao longo de vários anos, acabou contribuindo para a degradação do açude, como pode ser observado na Figura 1, em um resgate histórico de imagens de 1970 em comparação com as atuais de 2021, ficando evidente o quanto o leito do manancial foi afetado em um período de 51 anos.

O assoreamento do açude e o excesso de vegetação provocam cada vez mais a degradação do ambiente aquático, trazendo prejuízos irreversíveis a todo o ecossistema. É observado diversas barracas instaladas as margens do açude, onde são desenvolvidas atividades de pesca. Saliente-se que próximo as barracas, existe uma galeria para saída de esgoto.

Outro problema preocupante é a grande quantidade de lixo espalhado pelo manancial. O descarte incorreto por parte de empresas e da própria população, agrava ainda mais os índices de degradação do açude.

Figura 1. Comparativo entre imagens do açude em 1970 e dias atuais.

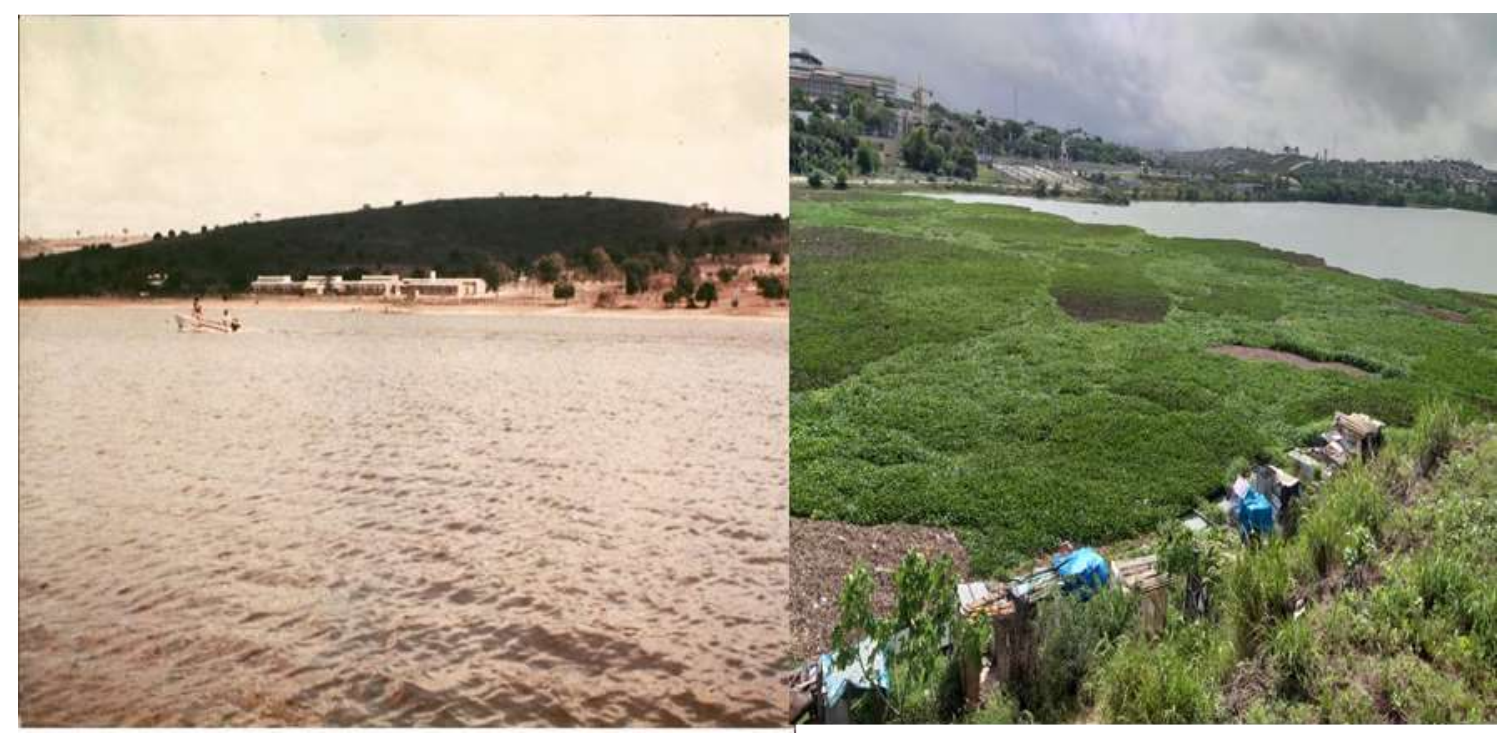

Fonte: Retalhos Históricos de Campina Grande (1970).

O assoreamento do açude e o excesso de vegetação provocam cada vez mais a degradação do ambiente aquático, trazendo prejuízos irreversíveis a todo o ecossistema. É observado diversas barracas instaladas as margens do açude, onde são desenvolvidas atividades de pesca. Saliente-se que próximo as barracas, existe uma galeria para saída de esgoto. 
Outro problema preocupante é a grande quantidade de lixo espalhado pelo manancial. O descarte incorreto por parte de empresas e da própria população, agrava ainda mais os índices de degradação do açude.

É corriqueiro a utilização das águas do açude para lavagem de veículos, sobretudo carros e caminhões, inclusive caminhões de transportes de aves, ocorrendo a liberação de fezes e urinas, além de graxas e óleos na água. Esse fato foi observado por Andrade et al (2014), afirmando que a lavagem desses veículos proporciona a contaminação da causando impactos como a impermeabilização do solo, impedindo a infiltração da água e podendo resultar em destruição da vegetação no entorno.

De acordo com a CETESB (2016), óleos e graxas são raramente encontrados em águas naturais, sendo normalmente oriundos de despejos e resíduos industriais, esgotos domésticos, efluentes de oficinas mecânicas, postos de gasolina, estradas e vias públicas.

O lançamento dessas substâncias em mananciais pode acarretar a diminuição do oxigênio dissolvido na água e acarretando ainda mais prejuízos a comunidade aquática (CETESB, 2016). A legislação brasileira não define um limite de concentração para óleos e graxas. Esta recomenda, por meio da Resolução do CONAMA 357/05, que estes estejam virtualmente ausentes para os corpos d'água de classes 1, 2 e 3 tolerando iridescências na classe 4 .

De acordo com os resultados obtidos na pesquisa, com amostras coletadas em 05/04/2021, a água do Açude de Bodocongó não pode ser utilizada para potabilidade, segundo a Portaria do Ministério da Saúde (MS) 518/04 (BRASIL, 2004), e nem balneabilidade segundo preconiza a Resolução 274/2000 do CONAMA (BRASIL,2000). O açude apresenta o número de coliformes totais maior que 2,1 x 103 NMP/100mL e Escherichia Coli de 2,2 x 103 .

Segundo a Portaria de consolidação GM/MS N. 888 de 4 de maio de 2021, que altera a Portaria de consolidação n. 5 Anexo XX de setembro de 2017, a Escherichia Coli é um microrganismo tido como habitante natural da flora microbiana do trato intestinal de humanos e da maioria dos animais de sangue quente, sendo, portanto, normalmente encontrado nas fezes destes animais.

O pH apresentou valor de 7,7 sendo considerado alcalino. Carvalho et al (2008) em pesquisa no Açude de Bodocongó encontrou valores entre 6,7 a 9,3 portanto uma referência básica. Diniz et al (2007) também encontrou valores básicos para o pH do mesmo manancial.

De acordo com a Resolução CONAMA 357/2005 (Brasil, 2005), para enquadramento dos corpos hídricos de água, o Açude de Bodocongó está enquadrado na classe I salobra, que é função da salinidade que apresentou um valor de $1744 \mathrm{dS} / \mathrm{cm}$ à $25^{\circ} \mathrm{C}$. Ações antrópicas como desmatamento, despejo de esgoto sanitário, efluentes industriais, agropecuários e mineração, fazem com que o escoamento superficial aumente a turbidez da água resultando em grandes alterações no ecossistema aquático.

Isso ocorre devido à redução da fotossíntese de plantas aquáticas, principalmente do fitoplâncton e das macrófitas submersas, suprimindo a produtividade de peixes e afetando adversamente os usos doméstico, industrial e recreacional (CESTEB, 2009).

O fósforo total apresentou valor de $20,4 \mathrm{mg} / \mathrm{L}$, valor aproximadamente dez vezes maior do que o valor médio, encontrado por Carvalho et. al. (2008) de $2 \mathrm{mg} / \mathrm{L}$. Sendo, portanto, superior ao recomendado pela Resolução 357/2005 do CONAMA que é de $0,124 \mathrm{mg} / \mathrm{L}$.

Quanto ao índice trófico (IET) o manancial é caracterizado como hipereutrófico adequado apenas para irrigação e produção de energia (Von Sperling,1997). Segundo CETESB (2007) lagos Hipereutróficos são corpos d'água afetados significativamente pelas elevadas concentrações de matéria orgânica e nutrientes, com comprometimento acentuado nos seus usos, associado a episódios florações de algas ou mortandades de peixes, com consequências indesejáveis para seus múltiplos 
usos, inclusive sobre as atividades pecuárias nas regiões ribeirinhas.

A dureza total apresentou valor de 355,5 mg/L. Segundo MACÊDO 2002 classificada como muito dura (teores maiores que $300 \mathrm{mg} \mathrm{CaCO3/L).} \mathrm{Segundo} \mathrm{a} \mathrm{Organização} \mathrm{Mundial} \mathrm{de} \mathrm{Saúde,} \mathrm{uma} \mathrm{água} \mathrm{é} \mathrm{designada} \mathrm{por} \mathrm{água} \mathrm{muito} \mathrm{dura} \mathrm{quando}$ apresenta uma concentração em carbonato de cálcio superior a $180 \mathrm{mg} / \mathrm{L}$. Uma água com dureza acima de $180 \mathrm{mg} / \mathrm{L}$ de $\mathrm{CaCO} 3$, pode induzir à formação de incrustações nas canalizações.

O valor de alcalinidade obtido está enquadrado no intervalo de alcalinidade da maioria das águas naturais (entre 30 e $500 \mathrm{mg} / \mathrm{L}$ de $\mathrm{CaCO} 3$ ), e indica normalidade nos processos de decomposição da matéria orgânica, assim como na taxa de respiração dos microrganismos (Moraes, 2008).

Com relação aos sólidos totais dissolvidos, foi encontrado valor de 1321,9 mg/L. O excesso de sólidos na água pode afetar a comunidade aquática, alterando as condições de luminosidade da água interferindo no metabolismo dos organismos autotróficos submersos, por dificultar a realização da fotossíntese, consequentemente prejudicando também os demais organismos heterotróficos dependentes do oxigênio dissolvido produzido na fotossíntese para respiração. Quando contém menos de $500 \mathrm{mg} / \mathrm{L}$ é considerada satisfatória para o uso doméstico e para muitos fins industriais. Já acima de $1000 \mathrm{mg} / \mathrm{L}$ contém minerais que lhe conferem um sabor desagradável e a torna inadequada para diversos usos (Carvalho, Oliveira, 2003)

Os valores de nitrato, nitrito e amônia apresentaram valores de 0,60 mg/L, 0,037 mg/L, e 14,01 mg/L respectivamente. Valor de nitrato maior que o valor recomendado pela resolução 357/2005 do CONAMA de 0,40 mg/L. A avaliação da forma predominante de nitrogênio em um corpo hídrico possibilita a inferência sobre o atual estágio da poluição, tendo em vista que a poluição recente se associa ao nitrogênio na forma de amônia e a poluição mais antiga é relacionada aos nitratos (Von Sperling, 2005).

O açude apresenta números de coliformes totais maior que 2,1 x 103 NMP/100mL e Escherichia Coli de 2,2 x 103. Segundo Chapman e Kimstach (1996), o monitoramento de organismos patogênicos consiste em um componente essencial de qualquer avaliação de qualidade das águas, em que o uso possibilita a ingestão direta ou indireta de água.

Na Figura 2, os pontos em laranja indicam áreas com presença de água ou vegetação, enquanto os pontos em roxo indicam áreas de solo exposto ou áreas construídas. Quando comparados os anos, nota-se expansão de área construída na parte oeste e norte do açude no ano de 2021 em relação ao ano de 2007, evidenciando o aumento da área urbana. Os maiores valores de NDBI (Normalized Difference Built-up Index) foram concentradas em áreas já consolidadas devido ao adensamento da área construída. 
Figura 2. Distribuição espacial e temporal do índice NDBI nos anos 2007 e 2021.

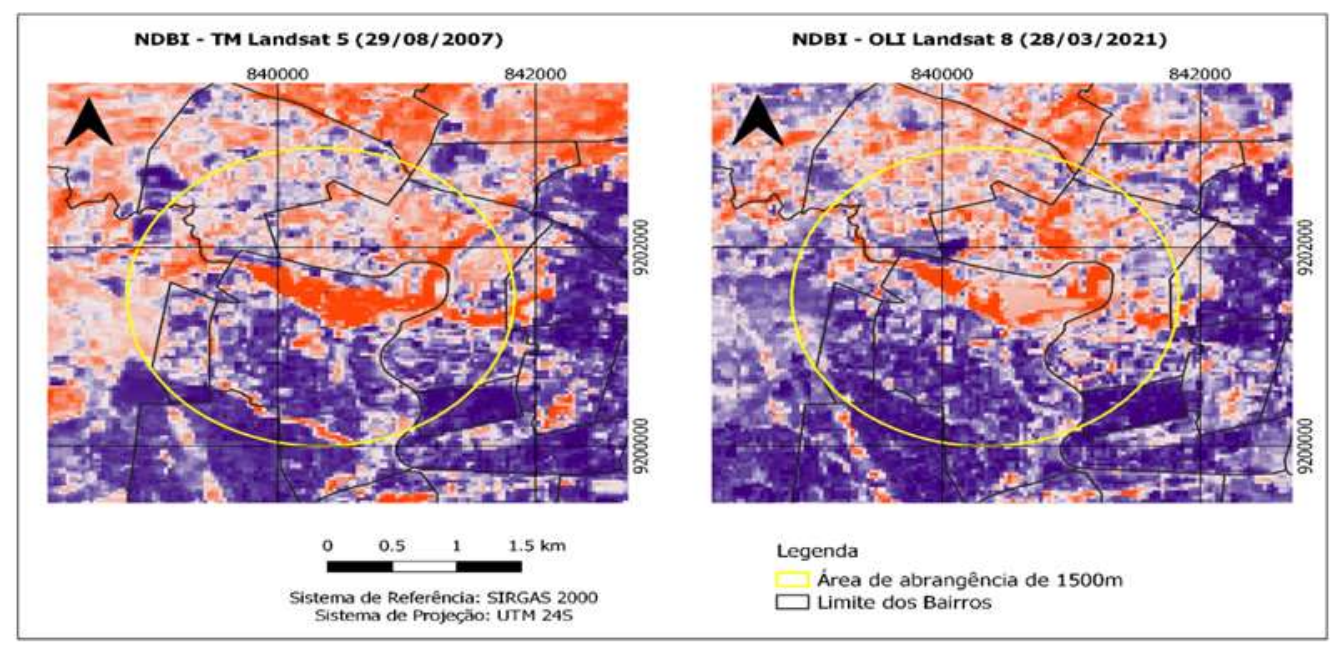

Fonte: Autores (2021).

Um dos fatores do aumento do NDBI na área foi justamente o Parque Ecológico de Bodocongó construído as margens do açude, mesmo sendo uma obra importante para o lazer da população no entorno não serve para minimizar os fatores de degradação do açude, tendo em vista que, as fontes pontuais e difusas continuam contaminando o manancial.

Os pesquisadores Medeiros e Morais Neto (2010), estudando a bacia do Açude de Bodocongó concluíram que a densidade populacional considerada alta nas proximidades, inclusive dentro da sua bacia hidrográfica, onde existe uma comunidade conhecida como Vila dos Teimosos.

Andrade et al (2014), Doroteu et al. (2012) e Ferreira e Velôso (2009), afirmam em suas respectivas pesquisas que a ocupação vem ocorrendo sem uma infraestrutura adequada, ocasionando uma superpopulação no local e consequentemente danos tanto a saúde dos moradores quanto ao açude. As invasões, como a Vila dos Teimosos, ocorreram principalmente pela falta de moradia e vulnerabilidade social. Essa falta de planejamento urbano nessa área contribuiu para a degradação da qualidade d'água do açude.

A faixa de valores resultantes do NDBI oscila entre -1 e 1, onde os valores com tendência negativa indicam a presença de áreas com vegetação. Os valores intermediários começam a determinar as áreas descobertas, áreas em crescimento ou em construção à medida que adquirem valores de tendência positiva elevados para indicar áreas territoriais com coberturas de solo edificadas ou infraestruturas antrópicas.

\section{Conclusão}

Atividades antrópicas, como despejo de efluentes domésticos e industriais, retirada de grande parte da vegetação nativa, lavagem de veículos, criação de animais e ocupação desordenada das áreas do seu entorno, contribuem de forma significativa para a sua degradação e poluição.

Dentre as principais fontes de poluição detectadas durante o período de realização da pesquisa podem ser citadas como fontes pontuais: lançamentos de esgotos domésticos e instalação de barracas no leito do açude para pesca, assim como as fontes difusas: arrastem de poluentes diversos e resíduos para dentro do açude, lavagem de carros, lançamento de esgoto industriais.

As águas do açude de Bodocongó não atendem ao que preconiza a Resolução 357/2005 para águas salobras nas classes 1,2 e 3. Incompatibilizando seu uso nas diversas atividades a exemplo de irrigação, aquicultura e pesca dentre outros 
sem um tratamento prévio. Quanto ao índice trófico (IET) o manancial é caracterizado como hipertrófico.

A variação temporal evidenciando o aumento da área urbana na área do entorno. Os maiores valores de NDBI foram concentradas em áreas já consolidadas devido ao adensamento da área construída. A geração do NDBI mostrou-se eficiente na caracterização da urbanização no entorno do açude de Bodocongó.

A falta de gestão pública principalmente tem contribuído para a degradação do Açude de Bodocongó ao longo dos anos. O aumento populacional em volta do açude, criação de Parque público e condomínios habitacionais e a falta de fiscalização trouxeram grandes impactos na bacia do corpo d'água.

Para que seja possível combater, recuperar e preservar este açude tão histórico e importante para a Cidade de Campina Grande, se faz necessário algumas medidas, sendo sugestões:

Atuação mais rigorosa do poder público em relação à fiscalização dos efluentes despejados no riacho de Bodocongó;

Implantação e conscientização ambiental da população através de campanhas educativas;

Implantação de estações de tratamento de esgotos domésticos em pontos estratégicos da cidade, assim como realização de todas as etapas essenciais para a amenização da carga poluidora dos efluentes;

Conscientizar a população sobre os riscos de balneabilidade, ingerir a água e consumir animais aquáticos provenientes do açude;

Planejar e executar projeto de recuperação da mata ciliar, sobretudo com resgate das espécies nativas da flora paraibana e retirada de espécies invasoras.

\section{Referências}

Agência Nacional de Águas (Brasil). Índice de qualidades das águas. Portal da qualidade das águas. Brasil, 2009.

Andrade, L. R. S., Andrade, M. Z. S. S., Fernandes, M. S. M., Alves, R. V., \& Barbosa, T. L. A. 2014. Estudo físico-químico da qualidade da água do açude de Bodocongó, Campina Grande -PB. XII Simpósio Ítalo-Brasileiro de Engenharia Sanitária e Ambiental. Natal-RN.

CETESB (2007). Relatório de Qualidade das Águas Interiores no Estado de São Paulo: 2006. São Paulo: CETESB, 2007.

CETESB. Óleos e Graxas. 2016. https://cetesb.sp.gov.br/

Costa, T. C. F. 2011. Ações antrópicas de impactos negativos no açude de Bodocongó no município de Campina Grande - Paraíba. Revista Brasileira de Informações Científicas. 2(2), 78-89.

Carvalho, A. P., Moraes Neto, J. M., Antunes de Lima, V. L., Souza, R. F., Silva, D. G. K. G., \& Araujo, F. P. 2008. Aspectos qualitativos do açude de Bodocongó em Campina Grande - PB.v.5. n.2.

Carvalho, A. R., \& Oliveira, M. C. V. 2003. Princípios básicos de saneamento do meio. (3ª ed.): Editora SENAC.

Chapman, D., \& Kimstach, V. 1996. Selection of water quality variables. Water quality assessments - a guide to use of biota, sediments and water in environmental monitoring. (2a.ed.): UNESCO/WHO/UNEP, 1996.

Da Paraíba, Paraíba - Governo do Estado. Secretaria de Estado da Ciência e Tecnologia e do Meio Ambiente, SECTMA; Agência Executiva de Gestão de águas do Estado da Paraíba, AESA.

Doroteu, H. G. F., Silvana, F. N., José, A. S. J., Janivan, F. S., \& José, G. V. B. (2012). Uso e ocupação nas margens do açude Bodocongó/PB. Revista Educação Agrícola Superior. 27(1), 70-75.

Ferreira, E. X., \& Velôso, T. M. G. (2009). A luta por moradia e o surgimento da Vila dos Teimosos: uma análise a partir de relatos orais. Anais XV encontro nacional da ABRAPSO. Maceió-AL.

Francisco, P. R. M., et al. 2015. Mapeamento da aptidão edáfica para fruticultura segundo o zoneamento agropecuário do Estado da Paraíba. Embrapa Algodão-Artigo em periódico indexado, 2015.

Guia nacional de coleta e preservação de amostras: água, sedimento, comunidades aquáticas e efluentes líquidas / Companhia Ambiental do Estado de São Paulo; Organizadores: Carlos Jesus Brandão et al. São Paulo: CETESB; Brasília: ANA, 2011.

Instituto Brasileiro de Geografia e Estatística (IBGE). Censo Brasileiro de 2010. Rio de Janeiro: IBGE, 2012.

Lamparelli, M. C. 2004. Grau de trofia em corpos d'água do Estado de São Paulo: avaliação dos métodos de monitoramento. São Paulo (BR). 2004. Tese (Doutorado) - Instituto de Biociências, Universidade de São Paulo, São Paulo. 
Research, Society and Development, v. 10, n. 13, e76101321067, 2021

(CC BY 4.0) | ISSN 2525-3409 | DOI: http://dx.doi.org/10.33448/rsd-v10i13.21067

Macêdo, J. A. B. (2002). Introdução à química ambiental. CRQ-MG. Juiz de Fora.

Ministério do Meio Ambiente. CONAMA. Resolução $N^{\circ}$ 274, de 29 de novembro de 2000. Define os critérios de balneabilidade em águas brasileiras.

Ministério do Meio Ambiente. Conselho Nacional do Meio Ambiente - CONAMA. Resolução 357. Brasília, 2005.23 p.

Ministério do Meio Ambiente. CONAMA. Resolução $N^{o} 357$, de 17 de março de 2005. Dispõe sobre a classificação dos corpos de água e diretrizes ambientais para o seu enquadramento, bem como estabelece as condições e padrões de lançamento de efluentes, e dá outras providências.

Ministério da Saúde. Portaria $n^{\circ}$ 2914, de 12 de dezembro de 2011. Dispõe sobre os procedimentos de controle e de vigilância da qualidade da água para consumo humano e seu padrão de potabilidade. Diário Oficial da União: República Federativa do Brasil, Poder Executivo, Brasília, DF, 148(239), 14 dez. 2011. Seção 1, p. 39-46. http://pesquisa.in.gov.br/imprensa/jsp/visualiza/index.jsp?jornal=1\&pagina=39\&data=14/12/2011>.

Ministério da Saúde. Fundação Nacional de Saúde. Cianobactérias tóxicas na água para consumo humano na saúde pública e processos de remoção em água para consumo humano. Brasília, 2003. 56 p.

Moraes Neto, J. M., \& Medeiros, S. S. (2010). Análise do assoreamento da bacia do riacho de Bodocongó, Campina Grande - PB. $2^{\circ}$ Congresso Internacional de Tecnologias para o Meio Ambiente Bento Gonçalves - RS, Brasil, 28 a 30 de abril.

Moraes Neto, J. M., Vasconcelos, L. M. S. X., Fernandes, M. F., \& Silva, M. J. (2016). Estudo dos riscos a desastres no entorno do açude de Bodocongó. Congresso Técnico Científico da Engenharia e da Agronomia CONTECC 2016. Foz do Iguaçu - PR 29 de agosto a 1 de setembro.

Rebouças, A. da C. (2004). Uso inteligente da água. São Paulo: Ed. Escrituras.

Guia nacional de coleta e preservação de amostras: água, sedimento, comunidades aquáticas e efluentes líquidas - Companhia Ambiental do Estado de São Paulo; Organizadores: Carlos Jesus Brandão et al. - São Paulo: CETESB; Brasília: ANA, 2011.

Steves, F. A. (1988). Fundamentos de Limnologia. Rio de Janeiro: Editora Interciência. 574p.

Von Sperling, M. (2005). Introdução à qualidade das águas e ao tratamento de esgotos. Princípios do tratamento biológico de águas residuárias. ( $3^{\mathrm{a}}$ edição), volume 1. Departamento de Engenharia Sanitária e Ambiental, Universidade Federal de Minas Gerais - UFMG. 